Ijtimaiya : Journal of Social Science Teaching, Vol. 4 No. 2 Tahun 2020

IJTIMAIYA Program Studi Tadris Ilmu Pengetahuan Sosial Institut Agama Islam Negeri Kudus

http://journal.stainkudus.ac.id/index.php/Ijtimaia p-issn: 2580-8990

\title{
Artificial Intellegence dengan Pembentukan Nilai dan Karakter di Bidang Pendidikan
}

\author{
Ferani Mulianingsih $^{\text {a, } 1}$, Khoirul Anwar ${ }^{\text {b, } 2}$, Fitri Amalia Shintasiwi ${ }^{\text {c,3 }}$, Anggi Jazilatur Rahma ${ }^{\mathrm{d}, 4}$ \\ âniversitas Negeri Semarang, feranigeographer@mail.unnes.ac.id \\ ${ }^{b}$ Universitas Negeri Semarang, irulanwar@mail.unnes.ac.id \\ ${ }^{c}$ Universitas Negeri Semarang, shintasiwi@ mail.unnes.ac.id \\ ${ }^{\mathrm{d}}$ Universitas Negeri Semarang, anggijheer@students.unnes.ac.id
}

\begin{tabular}{ll}
\hline & ABSTRAK \\
\hline Kata Kunci: & Artficial Intellegence merupakan cabang ilmu komputer yang menekankan pengembangan \\
Artificial & intelijen mesin, pola berpikir dan bekerja seperti manusia. Misalnya, pengenalan suara, \\
Intellegence & pemecahan masalah, pembelajaran, dan perencanaan. AI merupakan bagian cabang sistem \\
Nilai \& Karakter & literasi digital yang memiliki peranan besar dalam proses pengembangan intelegen. Dalam \\
Pendidikan & bidang pendidikan pun juga perlu memerlukan upaya inovasi dalam media pembelajaran, dan \\
Teknologi & salah satunya penerapan AI. Tujuan dilakukannya penelitian ini adalah untuk meningkatkan \\
& kualitas belajar siswa dan penanaman nilai beserta karakter selama beradaptasi dengan sistem \\
& AI. Metode yang digunakan menggunakan metode eksperimental untuk mengetahui \\
& bagaimana adaptasi dan respons siswa mengenai sistem basis tersebut dalam mengatasi \\
& permasalahan yang terjadi. AI memudahkan siswa dan mahasiswa dalam menunjang \\
& studinya secara visibilitas dan komprehensif. Artificial Intellegence memang menciptakan \\
& pola pikir siswa lebih kritis dan jeli, namun tidak sepenuhnya akan menjamin nilai serta \\
& karakternya baik. Jadi, perlunya sebuah bimbingan dan arahan langsung dari tenaga pendidik \\
& yang dibarengi dengan penggunaan fitur berbasis artificial intellegence.
\end{tabular}

\begin{tabular}{|c|c|}
\hline & ABSTRACT \\
\hline $\begin{array}{l}\text { Keyword: } \\
\text { Artificial } \\
\text { Intelligence } \\
\text { Value \& } \\
\text { Character } \\
\text { Education } \\
\text { Technology }\end{array}$ & $\begin{array}{l}\text { Artificial Intelligence with the Formation of Values and Character in the Field } \\
\text { of Education. Artficial Intelligence is a branch of computer science that } \\
\text { emphasizes the development of machine intelligence, thinking patterns and } \\
\text { working like humans. For example, voice recognition, problem solving, learning } \\
\text { and planning. AI is a branch of the digital literacy system that has a major role in } \\
\text { the intelligence development process. In the field of education it also needs } \\
\text { innovation efforts in learning media, and one of them is the application of AI. The } \\
\text { purpose of this research is to improve the quality of student learning and to instill } \\
\text { values and character while adapting to the AI system. The method used uses } \\
\text { experimental methods to find out how adaptation and student responses to the base } \\
\text { system in overcoming the problems that occur. AI makes it easy for students and } \\
\text { students to support their studies in a visibility and comprehensive manner. Artificial } \\
\text { Intelligence does create a student's mindset to be more critical and observant, but it } \\
\text { will not completely guarantee good grades and character. So, there is a need for } \\
\text { direct guidance and direction from educators coupled with the use of artificial } \\
\text { intelligence-based features. }\end{array}$ \\
\hline
\end{tabular}

\section{Pendahuluan}

Revolusi Industri 4.0 merupakan zaman dimana manusia dituntut untuk lebih maju dalam berteknologi baik dalam bidang industri maupun pendidikan. Dalam pendidikan, perlu adanya sebuah inovasi dalam mendorong kemajuan yang sebenarnya. Dan hal tersebut dapat dilakukan dengan upaya literasi digital masa kini. 
Menurut Paul Gilster dalam bukunya yang berjudul Digital Literacy (1997), literasi digital diartikan sebagai kemampuan untuk memahami dan menggunakan informasi dalam bentuk dari berbagai sumber yang sangat luas yang diakses melalui piranti komputer. Bawden (2001) menawarkan pemahaman baru mengenai literasi digital yang berakar pada literasi komputer dan literasi informasi. Literasi komputer berkembang pada dekade 1980-an, ketika komputer mikro semakin luas dipergunakan, tidak saja di lingkungan bisnis, tetapi juga di masyarakat. Namun, literasi informasi baru menyebar luas pada dekade 1990-an manakala informasi semakin mudah disusun, diakses, disebarluaskan melalui teknologi informasi berjejaring. Dengan demikian, mengacu pada pendapat Bawden, literasi digital lebih banyak dikaitkan dengan keterampilan teknis mengakses, merangkai, memahami, dan menyebarluaskan informasi.

Dalam bidang pendidikan, sering kerap terjadi sebuah permasalahan pola pembelajaran yang mencakup metode dan strategi pembelajaran yang kurang komprehensif. Baik siswa maupun mahasiswa sering kali salah tafsir dalam memahami materi yang diberikan, bukan merupakan sebuah kesalahan yang mutlak bagi pendidiknya maupun anak didiknya. Namun, perlu adanya sebuah sistem inovasi yang dapat meningkatkan kualitas pola pikir dan kompetensi sehingga dapat meminimalisir kejadian tersebut. Dengan demikian, perihal tersebut akan membawa dampak pada tingkat atau persentasi keberhasilan dalam tujuan pendidikan. Sehingga, akan lebih berkualitas mutunya apabila terdapat sebuah sistem yang mensupportnya seperti artificial intellegence. Kecerdasan Buatan atau Artificial Intelegence (AI) adalah cabang ilmu komputer yang menekankan pengembangan intelijen mesin, pola berpikir dan bekerja seperti manusia. Misalnya, pengenalan suara, pemecahan masalah, pembelajaran, dan perencanaan.

Di Indonesia sendiri belum mencapai tingkat persentase yang cukup tinggi dalam hal mengadopsi Artificial Intelegence, dengan demikian perlu adanya genjotan sistem tersebut dalam bidang pendidikan.

Tujuan dengan adanya gerakan teori Artificial Intellegence adalah agar memahami benar apa itu kecerdasan dan membuat mesin lebih bermanfaat dalam pendidikan untuk memudahkan siswa dalam pembelajaran sesuai dengan pengalamannya. Mencipatakan kualitas beajar siswa lebih baik dan upaya penerapan pembentukan nilai beserta karakter siswa dan mahasiswa. Pendidikan tidak hanya berkaitan dengan kompetensi kuantitatif siswa maupun mahasiswa, namun juga berhubungan dengan nilai dan karakter yang diperoleh selama mereka mengenyam pendidikan.

Menurut artikel yang disusun oleh Billy, dkk (2017) dengan judul "Implementasi Artificial Intellegence pada Game Defender of Metal City dengan menggunakan Finite State Machine" menyatakan bahwa game adalah jenis perangkat lunak yang populer dewasa ini. Pada game biasa terdapat Artificial Intellegence (AI) yang mengendalikan pihak komputer sehingga manusia yang bermain dapat merasakan seolah mereka sedang melawan pemain manusia lain saat bermain. Salah satu jenis game yang ada ialah tower defense dimana pemain perlu mempertahankan tower atau markasnya agar tidak dihancurkan oleh pihak lawan. Untuk membuat AI untuk game berjenis tower defense, diperlukan algoritmayang baik untuk mengatur gerakan pasukan lawan. Penelitian ini mengusulkan penerapan AI pada game berjenis tower defense menggunakan rule based Finite State Machine. Setiap pasukan memiliki AI dengan beberapa state, pada saat terjadi suatu kondisi tertentu, maka pasukan akan berpindah dari satu state ke state lainnya berdasarkan rule yang telah ditentukan, hanya ada satu state yang bisa aktif pada suatu waktu. Pada penelitian ini AI akan dibagi menjadi 3 level yaitu easy, medium, dan hard. Pengujian dilakukan dengan mempertandingkan antar level AI pada semua kemungkinan tingkat kesulitan, lalu dibuat tabel derajat kemenangan atau winning rate dari $\mathrm{AI}$ yang ada. Berdasarkan hasil pengujian Finite State Machine dapat diterapkan pada game 
berjenis tower defense baik untuk membentuk AI yang kuat.

Artificial Intellegence (AI) atau kecerdasan buatan menjadi penggerak revolusi industri 4.0 yang menjanjikan banyak kemudahan pemerintah maupun industri. Internet of Things (IoT) dengan big data contohnya dimana AI dapat diimplementasikan, teknologi yang telah banyak diadopsi di era industri 4.0 ini mampu menghubungkan setiap erangkat, seorang dapat mengotomatisasi semua perangkat tanpa harus berada di lokasi, lebih dari itu, saat ini telah banyak mesin yang dapat menginterpretasi suatu kondisi atau kejadian tertentu dengan bantuan AI, sebagaimana telah kamera cerdas pendeteksi kepadatan volume kendaraan di jalan raya menggunakan teknologi Deep Learning Neural Network, yang telah diimplementasikan pada beberapa Pemerintah Derah Kabupaten dan Kota dalam mendukung program Smart City yang telah dicanangkan. Pada sektor industri, banyak juga dari mereka yang telah mengotomatisasi mesin produksi dan manufaktur robot dan Artificial Intellegence, sehingga Industri 4.0 akan meningkatkan daya saing melalui perangkat cerdas, setiap entitas yang mampu menguasai teknologi ini disitulah keunggulan kompetitifnya (competitive advantage). Namun di tengah perkembangan industri 4.0 yang cukup masif pemerintah harus bergerak cepat dalam mengadopsi platform ini, jika tidak, mereka akan menurunkan efisiensi proses bisnis untuk menjaga stabilitas layanan publik. Oleh sebab itu diperlukan keilmuan dan pemahaman yang benar bagi pemerintah dalam menghadapi era Industri 4.0, dimana Chief Information Officer (CIO) dapat mengambil peranan penting dalam memberikan dukungan.

Menurut Kirana, dkk (2020) menyatakan bahwa Artifisial Intellegence (AI) atau kecerdasan buatan telah berkembang pesat dalam dekade terakhir. Penggunanya banyak diimplementasikan di lintas sektor seperti Badan Usaha Milik Negara (BUMN), Universitas, dan Pemerintahan. Studi menggunakan StrenghtWeakness-Opportunity Threat (SWOT) untuk mengukur implementasi AI. Sampel ditujukan pada inkubator bisnis pemerintah dan BUMN, selain itu juga menggunakan analisis konten terhadap beberapa implementasi AI yang ada. Hasil penelitian menunjukkan bahwa peningkatan efektivitas dan efisiensi perusahaan merupakan faktor utama yang mendorong tingginya tingkat implementasi AI. Namun implementasi dan pengembangan teknologi AI akan kurang maksimal jika tidak diperhatikan dengan detil atau disandingkan dengan teknologi lain (teknologi pangan dan lain-lain).

Perbedaan dengan tulisan yang peneliti lakukan adalah Artificial Intellegence dengan pembentukan nilai dan karakter di bidang pendidikan, khususnya pendidikan IPS dengan memanfaatkan social legacy.

\section{Metode}

Metode dalam penelitian kali ini menggunakan metode eksperimental. Dimana dalam pengupayaan gerakan Artificial Intellegence perlu melakukan eksperimen untuk bidang pendidikan. Metode ini disesuaikan dengan minat siswa, kemampuan siswa dan pengalaman belajar siswa terlebih dalam pengoperasian teknologi berbasis e-learning serta terhadap respon siswa kedepannya yang berkaitan dengan nilai karakter. Hal ini dilakukan untuk mempertajam algoritma ketika siswa mengakses fitur atau informasi pendidikan. Selain itu, AI dapat juga disederhanakan saat melakukan proses preparing data for analytics, pengembangan model sesuai algoritma yang kemudia di integrasikan serta di interprestasikan ke dalam sebuah produk sistem. Selain itu, dapat mengodekan proyek yang menggabungkan SAS dengan bahasa lain, termasuk Python, R, Java, atau Lua.

\section{Hasil dan pembahasan}

Perkembangan ilmu pengetahuan dan teknologi informasi mengalami pertumbuhan pesat memberikan dampak positif bagi umat manusia. Salah satu perkembangan teknologi yang sampai saat ini terus berkembang yaitu internet. Secara langsung mempengaruhi kebutuhan pokok akan informasi dalam 
kehidupan manusia saat ini karena informasi sangat mudah didapat dalam berbagai aspek kehidupan manusia. Perkembangan di bidang ilmu pengetahuan dan teknologi informasi senantiasa diikuti dengan adanya dampak baik secara langsung maupun tidak. Kemajuan teknologi informasi, masyarakat memiliki ruang gerak yang lebih luas. Aktifitas manusia yang semula bersifat nasional telah berubah menjadi internasional, peristiwa yang terjadi di suatu negara dalam hitungan detik sudah dapat diketahui oleh penduduk belahan dunia lainnya.

Kebutuhan akan keunggulan kompetitif di berbagai sektor strategis secara historis merupakan pendorong untuk pengembangan mekanisme baru yang lebih canggih dan cerdas serta hemat biaya dalam proses produksi dan penyediaan jasa. Dalam hal ini, dan sejak awal era industrialisasi, dari waktu ke waktu, lompatan tren teknologi terjadi dan merevolusi konsep produksi dan penyediaan jasa, hal ini yang disebut sebagai revolusi industri. Revolusi industri pertama terjadi di bidang mekanisasi dan mesin uap, revolusi industri kedua didasarkan pada penggunaan intensif energi listrik dan produksi massal, dan revolusi industri ketiga didirikan di lingkungan IT dan meluasnya domain digitasi.

Industri 4.0 sangat terkait dengan inovasi kreatif. Dalam beberapa dekade terakhir, inovasi menambahkan kompilasi melalui mobile application cloud computing, dan big data yang bersama-sama dapat membangun simbiosis yang sempurna, menciptakan konsep baru untuk proses simbiosis yang sempurna, menciptakan konsep baru untuk proses industrialisasi, dan menggeser model pasar ke era baru persaingan dan diferensiasi produk (Geiger \& Sa, 2013). Industri 4.0 mewakili pergeseran menuju ekonomi berbasis inovasi dengan ilmu pengetahuan, data, dan IoT sebagai konsep yang terpusat. Hal ini akan mempengaruhi struktur model saat ini, pasar, dan proses bisnis zaman industri serta membuka jalan menuju era baru digitalisasi, jaringan sistem, produksi yang "lebih pintar", dan proses bisnis yang saling berkaitan.
Ada tiga point yang merepresentasi revolusi industri 4.0 (Almada-Lobo, 2016; Schlectendahl, Keinert, Kretschmer, Lechler, \& Verl, 2015) (1) Digitalisasi produksi-sistem informasi untuk manajemen dan perencanaan produksi; (2) Otomatisasi-sistem untuk akusisi data dari jalur produksi dan menggunakan mesin; (3) Menghubungkan mesin manufaktur dalam rantai pasokan yang komprehensif dan pertukaran data otomatis.

Dibalik perkembangan industri 4.0, ada satu tren teknologi yang menjadi aktivator terhadap bergulirnya era ini, itulah Artificial Intellegence (AI) atau biasa disebut kecerdasan buatan. Pergeseran mekanisme dalam proses manufaktur akan diselesaikan dalam kerja mesin pintar yang berinteraksi satu dengan yang lain dengan pengguna. AI secara efektif dapat mengatasi tantangan yang dihadapi oleh industri manufaktur saat ini, melalui manufaktur adaptif yang didukung AI, kontrol kualitas otomatis, pemeliharaan prediktif, dan banyak lagi. AI dapat memberikan solusi seputar inspeksi visual, pengendalian dan otomatisasi, kalibrasi dan penyetelan, dan identifikasi masalah otomatis untuk mitra produsen besar. Mekanisme yang berjalan berupa algoritma machine learning, aplikasi, dan platform membantu produsen menemukan model bisnis baru, menyempurnakan kualitas produk, dan mengoptimalkan operasi manufaktur.

Penerapan AI di berbagai bidang kehidupan melahirkan tantangan tersendiri bagi dunia pendidikan. Perguruan tinggi berkejaran dengan waktu untuk mencetak sebanyak mungkin sarjana dengan kualifikasi di bidang AI demi memenuhi kebutuhan industri.

AI bekerja dengan menggabungkan sejumlah besar data dengan cepat, pengolahan berulang, dan algoritme cerdas, memungkinkan perangkat lunak untuk belajar secara otomatis dari pola atau fitur dalam data. AI adalah bidang studi luas yang mencakup banyak teori, metode, dan teknologi, serta sub bidang utama.

Kecerdasan buatan atau artificial intelligence (AI) kini telah dikembangkan besar-besaran sehingga teknologi ini akan 
meniru bahkan mengambil alih pekerjaan yang biasa dilakukan oleh manusia. Beberapa perusahaan teknologi telah menerapkan AI di antaranya Amazon, Facebook, Microsoft, hingga Google. Tetapi siapa sangka bahwa AI ini juga merambah ke dunia pendidikan. Pasalnya, sekolah-sekolah juga berkembang begitu juga teknologinya. Salah satunya adalah sebuah kursus akuntansi di Umass Lowell menggunakan buku teks online melalui software praktik. Pendiri Microsoft, Bill Gates sendiri merupakan salah satu pendukung penggunaan AI di bidang pendidikan. Gates behkan percaya AI akan memperbaiki pendidikan dalam banyak hal.

Pembelajaran dalam sistem AI ini merupakan pembelajaran yang dipersonalisasi sehingga meningkatkan pengalaman belajar siswa. Pembelajaran AI dalam sistem individual ini menunjukkan bahwa hal ini dapat meningkatkan fokus siswa. Pasalnya, AI memiliki kemampuan untuk mengajar siswa secara individu dan mengenali area yang dibutuhkan untuk menemukan cara pengajaran yang tepat pada siswa melalui kecerdasan buatan tersebut. Misalnya, jika teknologi ini tahu seseorang tertarik dengan mobil balap, maka itu yang akan digunakan sebagai analogi atau contoh untuk memahami materi pelajaran.

Kecerdasan AI bisa mengidentifikasi konsep seperti apa yang tidak dipahami oleh siswa. Sehingga nantinya AI bisa melakukan penyesuaian untuk menemukan cara baru dalam membantu pembelajaran siswa. Blackboard, salah satu alat di bidang pendidikan kini banyak digunakan perguruan tinggi. Sebuah platform online ini digunakan para profesor untuk merilis catatan, pekerjaan rumah, kuis, dan tes, dan memungkinkan siswa mengajukan pertanyaan dan tugas untuk penilaian. Alat ini juga bisa mengidentifikasi alasan di balik ketidak pahaman siswa.

Manfaat lain dari program AI yaitu menulai kedua pilihan ganda dan pertanyaan dengan jawaban singkat. Ke depannya, AI juga bisa menilai pertanyaan esai. Oleh sebab itu, para guru tidak perlu lagi menghabiskan waktu mengerjakan tugas menilai setiap jam karena guru dapat lebih berkonsentrasi pada pengajaran dan interaksi satu lawan satu saja. Siswa juga mendapat hasil nilai langsung melalui AI. Mereka tidak perlu menunggu waktu yang lama untuk mendapatkan nilai mereka. Siswa juga akan menuai keuntungan dari guru yang memiliki waktu tambahan untuk proses belajar dan mengajar.

Penerapan AI, di sisi lain, juga telah merambah sektor pendidikan, mulai dari pendidikan dasar hingga pendidikan tinggi, bahkan pendidikan profesi. AI diyakini dapat membantu manusia untuk belajar dengan lebih baik dan mencapai tujuan pendidikan yang diinginkannya. Dengan kata lain, nilai dan karakter di bidang pendidikan juga dipersoalkan.

Salah satu tantangan terbesar di dunia pendidikan selain cara dan kecepatan belajar yang berbeda-beda pada tiap individu adalah baik buruknya nilai yang tertanam di dalam diri mereka seusai beradaptasi menggunakan sistem berbasis artificial intellegence. Dampak yang diberikan juga memengaruhi perkembangan anak didik dalam bertindak, merespons dan menyikapi segala masalah yang ada. Baik nilai kejujuran hingga nilai kompetisi dan tanggung jawab. Secara umum aplikasi canggih berbasis IT membawa dampak yang sangat signifikan terhadap pola pikir dan pengetahuan umum siswa maupun mahasiswa, hal ini akan menuntut untuk berpikir kritis dan jeli, kemampuannya pun juga akan didukung dengan interaksi dan akses yang sangat maju. Namun, hal-hal buruk pun juga dapat terjadi seperti kebiasaan duplikat penuh tanpa memfilter terlebih dahulu.

Tantangan adanya penerapan Artificial Intellegence juga terletak pada nilai dan karakter, hal ini dapat ditunjukkan dengan adanya perlakuan dan kontrol terhadap pengelolaan dan penggunaan aplikasi pendidikan berbasis artificial intellegence. Peran pendidik, orang tua dan pemerintah juga memegang penuh dalam pengawasan anak didik agar menggunakan media aplikasi tersebut secara bijak dan profesional. Perlunya penanaman nilai dan karakter agar sistem 
artficial intellgence berjalan lancar dan sebagai mana mestinya.

Beberapa kasus sebelumnya juga teah terjadi dengan adanya media pembelajaran berbasis IT juga malah justru menjebak siswa ke dalam habbit yang buruk. Dengan begitu perlu adanya security apps yang memungkinkan siswa atau mahasiswa agar tidak melakukan kecurangan seperti tindak plagiasi penuh dan pelanggaran hak cipta. Berdasarkan kasus sebelumnya, diketahui bahwa terdapat data-data duplikat yang tidak sedikit oleh karena itu media berbasis IT atau Artificial Intellegence ini belum sepenuhnya menjamin kebiasaan baik siswa dalam beradapatasi dengan teknologi. Perlunya pendidikan nilai dan karakter yang fundamental untuk membarengi kemajuan sistem pendidikan tersebut.

\section{Simpulan}

Artificial Intellegence merupakan cabang ilmu komputer yang menekankan pengembangan intelijen mesin, pola berpikir dan bekerja seperti manusia. Misalnya, pengenalan suara, pemecahan masalah, pembelajaran, dan perencanaan. AI juga bisa diterapkan pada bidang pendidikan yang berdampak pada nilai dan karakter anak didik yakni baik siswa maupun mahasiswa untuk meningkatkan ketajaman pola pikir dan pandangan baru lainnya. AI memudahkan siswa dan mahasiswa dalam menunjang studinya secara visibilitas dan komprehensif namun secanggihnya Artificial Intellegence pun juga belum tentu menjadikan kebiasaan baik dalam beretika dalam berteknologi, sehingga tetap perlu adanya pendidikan dan pengajaran secara langsung dalam membimbing dan mengarahkan anak didiknya.

\section{Referensi}

Ahmad, Abu. "Mengenal artificial intelligence, machine learning, neural network, dan deep learning." no. October (2017).
Saat ini pun ada beberapa aplikasi pendidikan yang mengadopsi artificial intellegence seperti voice assistant yang memungkinkan siswa berinteraksi dengan materi pembelajaran tanpa harus berinteraksi dengan guru atau dosen, baik di ruang kelas maupun di rumah.

Selain memudahkan dalam penyampaian informasi serta interaksi, fitur tersebut juga dapat mengancam perilaku siswa dan mahasiswa yang berubah menjadi seorang yang pasif. Sehingga dapat disimpulkan bahwa secanggihnya Artificial Intellegence pun juga belum tentu menjadi kebiasaan baik dalam beretika dalam berteknologi, sehingga tetap perlu adanya pendidikan dan pengajaran secara langsung dalam membimbing dan mengarahkan anak didiknya.

Ahsani, E. L. F. (2020). Analisis Bahan Ajar Kurikulum 2013 Berbasis Multiple Intelligence Kelas IV. ELEMENTARY: Islamic Teacher Journal. 8(1).

Billy, Imam Kuswardayan, Wijayanti Nurul Khotimah. Implementasi Aritificial Intellegence pada Game Defender of Metal City dengan Menggunakan Finite State Machine. Jurnal Teknik Pomits Vol 6 No 2017.

Chanda Halim, Hendri Prasetyo. Penerapan Artificial Intellegence dalam Computer Aided Instructure (CAI). Jurnal Sistem Cerdas 2018 Vol 1 No 1, ISSN: 2622-8254, Hal: 45-51.

Hanik, E. U. (2019). Model Pengasuhan Alternatif Dual-Career Family Dalam Pemenuhan Kebutuhan Asuh. Indonesian Journal of Islamic Early Chilhood Education. 3(1). 111-122.

H. Toba, "Big Data: Menuju Evaluasi Era Informasi Selanjutnya", Conference Paper, April, 2015.

Kirana Rukmayuninda Ririh, Nur Laili, Adityo Wicaksono, Silmi Tsurayya. Studi 
Komparasi dan Analisis SWOT pada Implementasi Kecerdasan Buatan (Artificial Intellegence) di Indonesia. J@ti Undip Jurnal Teknik Industri Vol. 15 No. 2 Mei 2020.

M. Frank, P. Roehrig, B. Pring, "Apa yang harus dilakukan ketika mesin melakukan semuanya?", Elex Media Komputindo, 2017.

Nafisah, F. T., \& Zafi, A. A. (2020). Model Pendidikan Karakter Berbasis Keluarga Perspektif Islam di Tengah Pendemi Covid-19. Ta'allum: Jurnal Pendidikan Islam, 08(1), 1-20. https://doi.org/10.21274/taalum.2020.8 .1.1-20

Partono. (2020). Pendidikan Akhlak Remaja Dalam Keluarga Muslim di Era Industri 4.0. Jurnal Teladan: Jurnal Ilmu Pendidikan dan Pembelajaran. 5(1).

Y. Muhammad, "Era Industri 4.0: Tantangan dan Peluang Perkembangan Pendidikan Kejuruan Indonesia", Sidang Terbuka Luar Biasa Universitas Negeri Makasar, 14, 